\title{
ОГРАНИЧЕНИЕ ПРАВА НА ОСПАРИВАНИЕ НОТАРИАЛЬНО УДОСТОВЕРЕННОГО ЗАВЕЩАНИЯ
}

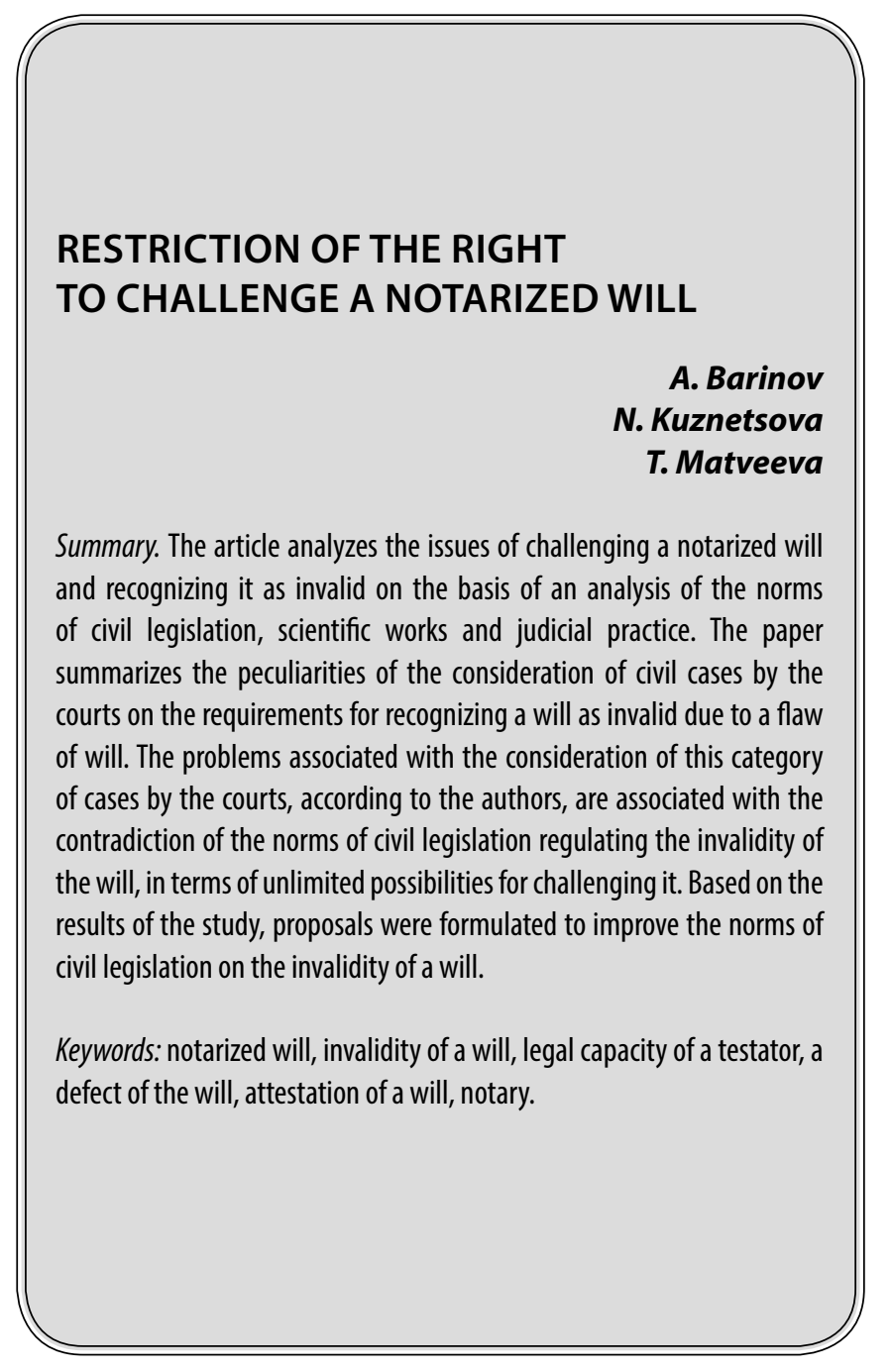

$\mathbf{0}$ дним из оснований наследования в гражданском законодательстве РФ является завещание. С вступлением в действие с 1 марта 2002 г. третьей части ГК РФ нормы о наследовании по завещанию получили ряд нововведений по сравнению с предшествующим гражданским законодательством. Причем в последнее время нормы о наследовании по завещанию получили новое развитие[1]. Если ранее составление завещание носило исключительно личный характер, то теперь возможно составить и совместное завещание, но только для граждан состоящим в зарегистрированном браке (п. 4 ст. 1118 ГК РФ). Более того, кроме завещания наследодатель наделен правом заключить наследственный договор с лицами, которые могут призываться к наследованию (ст. 1140.1 ГК РФ).
Баринов Андрей Викторович

К.ю.н., дочент, Владимирский филиал Российской академии народного хозяйства и государственной службы

barinov-vlad@inbox.ru

Кузнецова Наталья Александровна Старший преподаватель, ФКОУВО «Владимирский юридический институт ФСИН России» kuz1503@yandex.ru

Матвеева Тамара Павловна

Старший преподаватель, ФКОУ ВО «Владимирский юридический институт ФСИН России»

matveeva33@mail.ru

Аннотация. В статье на основе анализа норм гражданского законодательства, научных работ и судебной практики проанализированы вопросы оспаривания нотариально удостоверенного завещания и признания его недействительным. В работе обобщены особенности рассмотрения судами гражданских дел по требованиям о признании завещания недействительным вследствие порока воли. Проблемы, связанные с рассмотрением судами данной категории дел по мнению авторов связаны с противоречием норм гражданского законодательства регулирующие вопросы недействительности завещания, в части неограниченных возможностей по его оспариванию. По итогам исследования сформулированы предложения по совершенствованию норм гражданского законодательства о недействительности завещания.

Ключевые слова: нотариально удостоверенное завещание, недействительность завещания, дееспособность завещателя, порок воли удостоверение завещания, нотариус.

Что касается положений ГК РФ о наследовании по завещанию, действующих с момента принятия третьей части ГК РФ, то наибольшие трудности в судебной практике вызывают нормы о признании нотариально удостоверенного завещания недействительным ввиду их недостаточной теоретической проработки. Об остроте проблемы свидетельствует статистика рассмотрения судами общей юрисдикции этой категории дел размещенной на сайте Судебного департамента при Верховном Суде РФ [2]. Так в 2017 г. было принято 2273 исковых заявления о недействительности завещания, рассмотрено - 1528, из них удовлетворено - 413. В 2018 г. принято 2216, рассмотрено - 1562, удовлетворено - 451., а в 2019 г. принято 2161, рассмотрено - 1539, удовлетворено - 392. 
Если обобщить выводы авторов, сделанные на основе анализа судебных дел по рассмотрению исков о признании завещания недействительным, то можно выделить следующие процессуальные особенности, влияющие на принятие решения судом по делу.

Во первых, при оспаривании завещания в ходе рассмотрения дела суду на основе представленных доказательств необходимо установить следующие факты: имел ли завещатель психическое расстройство, степень его тяжести, наличие нарушений в интеллектуальной волевой сфере, в результате чего он не был способен понимать значение своих действий или контролировать свои действия в момент составления завещания. Для установления указанных фактов суд использует следующие доказательства: объяснения сторон, свидетельские показания (как правило это родственники, соседи, друзья, сослуживцы, работник медицинских и социальных организаций и др.); письменные доказательства (чаще всего это медицинские документы: медицинские заключения, амбулаторная карта и др.) [3, с. 25], объяснения нотариуса, удостоверившего завещание, заключение экспертов. Основная проблема при рассмотрении такой категории дел связана с тем, что необходимо доказать состояние человека, которого уже нет в живых.

Во-вторых, для установления и опровержения дефекта воли завещателя в момент составления завещания суды назначают посмертную судебную психологическую или судебную психиатрическую, либо, в зависимости от обстоятельств комплексную психолого-психиатрическую экспертизу. Важно отметить, что назначенная судебная экспертиза может дать однозначный ответ о психическом состоянии завещателя в момент совершения завещания только в том случае если в медицинских документах содержатся достаточные сведения о его поведении. Только в этом случае эксперты могут сделать вывод о наличие психических заболеваний, влияющих на способность завещателя осознавать свои действия и руководить ими в момент составления и подписания завещания [3, с. 26, 4, с. 38]. В силу этого суд назначает экспертизу, только в том случае если сторонами представлены документы, в которых содержатся достаточные сведения для установления дефекта воли у завещателя при совершении завещания [5 с. 104-105].

В третьих, существенной особенностью при рассмотрении дела о недействительности завещания является оценка собранных доказательств, которые влияют на принятие решения следующим образом.

1. Установление имеющих значение юридических обстоятельств, подтверждающих наличие или отсутствие психического расстройства у завещателя не может основываться только на показаниях свидетелей и объяснениях нотариуса, так как для однозначного определения таких фактов требуются специальные познания, которыми обладают только лица имеющие специальные познания в соответствующей области [6 с. 37], но не свидетели и нотариус, каковыми, как правило, ни свидетели, ни нотариус, ни суд не обладают. Более того, в некоторых случаях, когда с момента составления завещания и до момента рассмотрения дела в суде прошло много лет, показания свидетелей и объяснения нотариуса не могут быть приняты в качестве доказательств по делу, так как сведения сообщенные этими лицами не обладают качеством достоверности ввиду их противоречия, не точности и несоответствия реальным событиям. Кроме того, показания свидетелей могут не приниматься судом если есть сомнения в их беспристрастности, ввиду наличия родственных, дружеских, служебных, неприязненных или иных отношений между завещателем и свидетелями.

2. При принятии решения суд должен оценивать все допущенные к рассмотрению по делу доказательства в совокупности, причем заключение эксперта не носит исключительного характера и не может иметь приоритет по отношению к свидетельским показаниям и объяснению нотариуса. Как показывает судебная практика, если в заключении экспертов сделан неоднозначный вывод о наличии или отсутствии расстройства психики у завещателя в момент составления завещания, то на нем нельзя основывать судебное решение [7].

3. Наличие у дееспособного завещателя психического заболевания например, шизофрении, не всегда влечет принятия решения о признание завещания недействительным, если по заключению экспертов будет установлено, что наличие психического заболевание не повлияло на его способности в момент совершения завещания правильно понимать происходящее и руководить своими действиями [8].

Таким образом, иск о признании завещания недействительным подлежит удовлетворению если все исследованные доказательства по делу однозначно подтверждают факт наличия расстройства психики у завещателя в момент составления завещания, в результате чего он не мог понимать значение своих действий или руководить ими. При наличии противоречий между собранными доказательствами в иске должно быть отказано.

Проблемы возникающие при рассмотрении в судах исков о признании завещания недействительным обусловлены в первую очередь несовершенством норм гражданского законодательства регулирующих призна- 
ние завещания недействительным и процесса удостоверения завещания у нотариуса.

Так, раздел V ГК РФ содержат только общую норму о недействительности завещания (ст. 1131 ГК РФ) в которой не только не указаны какие либо основания для признания завещания недействительным, но нет даже отсылки к специальным нормам ГК РФ о недействительности сделок. Исходя из норм § 2 главы 9 ГК РФ, можно выделить следующие основания недействительности завещаний: нарушение требований предъявляемых к форме и содержанию завещания, порядку его удостоверения (ст. 169 ГК РФ), недееспособность и ограниченная дееспособность завещателя (ст. 171, 176 ГК РФ), а также порок воли завещателя (ст. 177, 179 ГК РФ). В отличие от сделок, совершаемых между гражданами, составление и удостоверение завещания осуществляется только у нотариуса или другого указанного в законе должностного лица (п. 1 ст. 1124 ГКРФ), то оспаривание завещания ввиду нарушения формы и содержания завещания, отсутствие дееспособности у завещателя, а также воздействия на завещателя третьих лиц в момент составления завещания (ст. 179 ГК РФ) вряд ли достигнет своей цели. Судебная практика по делам о недействительности завещания показывает, что одним из распространенных оснований по которому оспаривается завещание является факт нахождения завещателя в момент составления завещания в состоянии, когда он не мог понимать значение своих действий или руководить ими (ст. 177 ГК РФ). Как свидетельствует вышеприведенная статистика, только по 1/3 из рассмотренных дел судами выносится решение об удовлетворении иска, что обусловлено трудностями применения ст. 177 ГК РФ при оспаривании завещания при наличии следующих проблем.

Первая проблема обусловлена тем, что нормы ст. 177 ГК РФ направлены в первую очередь на защиту имущественных интересов живых граждан, которые в момент совершения сделки находились в таком состоянии, что не могли осознавать окружающую обстановку, не отдавали отчета своим действиям и не могли руководить ими. Такие состояний могут возникать по различным причинам, это сильные душевные волнения, нервные потрясения, вызванные трагическими событиями, различные хронические и психические заболевания, алкогольное или наркотическое опьянение. При совершении сделки в таком состоянии, сам гражданин, или заинтересованные лица могут требовать признания ее недействительной доказав факт нахождения в таком состоянии в момент совершения сделки. При признании же завещания недействительным, доказать наличие у завещателя в момент совершения завещания состояния, предусмотренного ст. 177 ГК РФ значительно труднее, так как доказывание происходит уже после его смерти, ввиду того, что закон не допускает оспаривать завещание до открытия наследства (п. 2 ст. 1131 ГК РФ).

Вторая проблема, которая возникает при оспаривании завещания на основании ст. 177 ГК РФ состоит В том, что завещание удостоверяется нотариусом, который обязан установить дееспособность завещателя на момент совершения завещания. К сожалению, в ст. 57 Основ законодательства Российской Федерации о нотариате от 11 февраля 1993 г. N4462-I [9] не содержится норм определяющих порядок и способы установления дееспособности завещателя. Этот пробел восполнен в Методических рекомендациях по удостоверению завещаний, принятию нотариусом закрытого завещания, вскрытию и оглашению закрытого завещания от 2004 г. (далее - Методические рекомендации) [10], где в п. 8 нотариусам даны указания по установлению дееспособности завещателя путём проверки документов, а способность завещателя отдавать отчёт в своих действиях путём проведения беседы с завещателем. Так в одном из судебным дел, вывод суда о дееспособности завещателя был основан на том, что во время беседы «перед составлением завещаний вела себя адекватно, понимала происходящее, самостоятельно прочитала завещания, то обстоятельство, что она через несколько дней после составления первого завещания пришла для составления второго завещания, также свидетельствует об осознанности действий» [11]. Так же, согласно п. 8 Методических рекомендаций нотариус должен отказать даже дееспособному гражданину в удостоверении завещания если он находится в состоянии, не позволяющим ему понимать значение своих действий или руководить ими (например, вследствие болезни, наркотического или алкогольного опьянения и т.п.).

В этой связи возникает вопрос, как нотариус при удостоверении завещания может установить наличие болезни, особенно психического заболевания, наркотического или алкогольного опьянения (которые, к примеру имели место до обращения к нотариусу, но последствия могут отразиться при составлении завещания) у завещателя, влияющие на его способность понимать значение своих действий или руководить ими без участия медицинских работников, медицинской документации и освидетельствования. Поэтому отказ нотариуса в удостоверении завещания при таких обстоятельствах будет основан исключительно на субъективном мнении нотариуса с большой вероятностью совершения ошибки при определении психического состоянии завещателя, так как однозначно такое состояние могут определить только лица, обладающие специальными познаниями.

Таким образом, при удостоверении завещания проверить дееспособность гражданина, установить его возможность осознавать свои действия и выяснить его волю 
о действительном и свободном намерении составить завещание нотариус может только путём проверки документов и проведения беседы с завещателем, что не может служить достоверными способами определения психического состоянии завещателя. Здесь следует отметить уязвимость позиции нотариуса, который с одной стороны должен определить дееспособность завещателя и психическое состояние завещателя, но с другой стороны ограничен в выборе способов. Он не может привлечь медицинских работников к данной процедуре, ввиду медицинской тайны не может запросить медицинские документы о состоянии здоровья завещателя из медицинской организации, провести освидетельствование на наличие наркотического или алкогольного опьянения.

В связи с этим установление норм дающих возможность признать судом любое составленное завещание недействительным по иску заинтересованного лица, с одной стороны является вполне оправданным. Но если взглянуть на проблему с другой стороны, то получается, что закрепление в ГК РФ нормы о признании любого завещания недействительным, по сути, дискредитирует деятельность нотариуса по удостоверению завещания. Тем самым законодатель не доверяет нотариусам и их возможностям однозначно установить может ли гражданин, обратившийся для составления завещания понимать значение своих действий или руководить ими. Тогда уместен другой вопрос, а зачем вообще нотариусу устанавливать психическое состояние завещателя при совершении завещания, если любое составленное завещание может быть признано недействительным, с учетом того, что нотариус не может даже точно определить и дееспособность гражданина, ввиду отсутствия какого либо реестра лиц, которые судом ограничены в дееспособности или признаны недееспособными.

Более того, нормы ГК РФ о признании любого завещания недействительным ставят под сомнение не только деятельность нотариуса, но и поведение самого завещателя и вступают в противоречие с принципом осуществления гражданских прав своей волей и в своем интеpece (п. 2 ст. 1, ст. 9 ГК РФ) и нормами о дееспособности граждан (ст. 21 ГК), в том числе по своей воле завещать свое имущество. Получается, что выражение воли гражданина о своем намерении определить судьбу имущества на случай смерти при удостоверении завещания не имеет юридического значения, так как после смерти может быть оспорено и признана недействительной.

Противоречивые и непоследовательные законодательные положения дающие неограниченные возможности по оспариванию любых нотариально удостоверенных завещаний приводят к росту количества судебных дел по данным спорам при рассмотрении которых стороны могут использовать различные, в том чис- ле и противоправные способы (фальсификация доказательств, уничтожение медицинских документов, сговор со свидетелями), чтобы опровергнуть волю завещателя, который уже никак не может повлиять на этот процесс. Такое правовое регулирование вряд ли следует считать нормальным, так как идет против воли завещателя, и наличие в судах общей юрисдикции большого количества дел по оспариванию завещаний обусловлено несовершенством и противоречием норм о недействительности завещания, вследствие отсутствия ограничений по признанию завещания недействительным.

Для устранения проблем связанных с рассмотрением указанной категории дел мы поддерживаем предложения высказанные рядом авторов [6 с. 39, 12, с. 43] о необходимости распространить ведение видеофиксации процесса совершения совместного завещания супругов (п. 5.1 ст. 1125 ГК РФ) и при совершении личного завещания, что может служить доказательством однозначно выраженной воли наследодателя и являться весомым объектом для исследования экспертами при подготовке заключения.

Но на наш взгляд реализация данного предложения является недостаточной для совершенствования норм ГК РФ о недействительности завещания. С целью устранения противоречия между правом граждан осуществлять гражданские права своей волей и в своем интересе, в том числе правом завещать свое имущество и возможностью оспаривания любого завещания целесообразно установить в гражданском законодательстве положения запрещающие оспаривать нотариально удостоверенные завещания совершенные при следующих обстоятельствах.

1. Если с момента совершения завещания до момента смерти завещателя прошло более трех лет. Как показывает судебная практика оспаривание завещаний совершенных за долго до смерти завещателя существенно затруднено, так как утрачивается достоверность таких видов доказательств как свидетельские показания и объяснение нотариуса. По прошествии времени эти лица могут уже плохо помнить какие либо детали и события необходимые для установления психического состояния завещателя. К моменту рассмотрения дела могут быть также утрачены и медицинские документы, необходимые для проведения экспертизы и отражающие состояние здоровья завещателя в момент совершения завещания

2. Завещания совершенные в пользу кого либо из наследников по закону. В этом случае, выбор наследодателем наследника, которому должно перейти имущество по завещанию осуществляется исходя из его личных отношений с этим наследником и имеются веские причины лишения 
наследства остальных наследников по закону. Допустить оспаривание таких завещаний означает пренебрежительное отношение к воле завещателя на выбор наследника. Но если, по каким то причинам наследодатель совершил завещание в пользу «посторонних лиц», не относящихся к наследникам по закону, или в пользу других субъектов, при наличие наследников по закону, то оспаривание завещание вполне допустимо, так как имущество «уходит» из семьи (родственников) и при оспаривании такого завещания можно установить мотивы такого поступка и пси- хическое состояние завещателя, влияющее на его действительность.

Таким образом, реализация указанных предложений в гражданском законодательстве позволит устранить противоречие между правом гражданина свободно выразить свою волю по переходу имущества после смерти и правом заинтересованных лиц оспорить выражение этой воли, содержащейся в завещании. Так же это позволит снизить количество обращений в суд с иском о недействительности завещания и соответственно снизить нагрузку на суды.

\section{ЛИТЕРАТУРА}

1. Федеральный закон от 19 июля 2018 г. N217-Ф3 «0 внесении изменений в статью 256 части первой и часть третью Гражданского кодекса Российской Федерации» // СЗ РФ/2018. N30, ст. 4552.

2. http://www.cdep.ru/index.php?id=79

3. Малкин 0.Ю., Осипов И.В. Особенности рассмотрения дел о признании завещания недействительным в связи с неспособностью завещателя понимать значение своих действий или руководить ими // Бюллетень нотариальной практики. 2010. N2. C. 25-28.

4. Вершкова Е. Оспаривание завещания по основаниям ст. 177 ГК РФ: проблемы доказывания // Жилищное право. 2015. N4. С. 33-42.

5. Марухно В.М. Посмертная экспертиза в вопросах недействительности завещания // 0бщество и право. 2011. N5. С. 104-105.

6. Смолина Л.А., Лебедева Е.А. Признание завещания недействительным по пороку субъективной стороны: проблемы правоприменительной практики // Нотариус. 2019. № 1. С. 35-39.

7. Апелляционное определение Смоленского областного суда от 21 июня 2016 г. по делу N33-2034/2016; Кассационное определение Саратовского областного суда от 4 мая 2011 г. по делу N33-2380 // Доступ из справ.-правовой системы «Консультант Плюс».

8. Апелляционное определение Свердловского областного суда от 29 марта 2018 г. по делу N A33-4851/2018. // Доступ из справ.-правовой системы «Консультант Плюс».

9. Ведомости съезда народных депутатов РФ и Верховного Совета РФ. 1993. № 10, ст. 357.

10. Утверждены решением Правления Федеральной нотариальной палаты. Протокол N04/04 от 1-2 июля 2004 г. // Доступ из справ.-правовой системы «Консультант Плюс».

11. Определение Судебной коллегии по гражданским делам Верховного Суда Республики Карелия 18 марта 2014 г. по делу N33-807/2014 по апелляционной жалобе на решение Петрозаводского городского суда Республики Карелия от 25 декабря 2013 г. по иску Т.Л.Ю., А.Н.В., А.И.В. к Д.Е.Ю., Д.А.С. о признании завещаний недействительными // Доступ из справ.-правовой системы «Консультант Плюс».

12. Нестолий В.Г. Главный и доказательственный факт по иску об оспаривании завещания в связи с адееспособностью // Наследственное право. 2018. N. C. 43-47. 